\title{
Kinetic Analysis and Quantification of the Dopamine Transporter in the Nonhuman Primate Brain with ${ }^{11}$ C-PE2I and ${ }^{18}$ F-FE-PE2I
}

\author{
Andrea Varrone ${ }^{1}$, Miklós Tóth ${ }^{1}$, Carsten Steiger $^{1}$, Akihiro Takano ${ }^{1}$, Denis Guilloteau ${ }^{2,3}$, Masanori Ichise ${ }^{4}$, Balázs Gulyás ${ }^{1}$, \\ and Christer Halldin ${ }^{1}$ \\ ${ }^{1}$ Karolinska Institutet, Department of Clinical Neuroscience, Centre for Psychiatry Research, Stockholm, Sweden; ${ }^{2}$ CHRU Tours, \\ Tours, France; ${ }^{3}$ INSERM, U 930, Tours, France; and ${ }^{4}$ Department of Radiology, CUMC PET Center, Columbia University, New York, \\ New York
}

\begin{abstract}
${ }^{18} \mathrm{~F}-(E)-N$-(3-iodoprop-2-enyl)-2 $\beta$-carbofluoroethoxy-3 $\beta$ (4'-methyl-phenyl)nortropane ( $\left.{ }^{18} \mathrm{~F}-\mathrm{FE}-\mathrm{PE} 2 \mathrm{I}\right)$ is a novel radioligand for dopamine transporter (DAT) PET. As compared with ${ }^{11} \mathrm{C}-N$-(3-iodoprop-2E-enyl)-2 $\beta$-carbomethoxy-3 $\beta$-(4-methylphenyl)nortropane ( $\left.{ }^{11} \mathrm{C}-\mathrm{PE} 2 \mathrm{I}\right),{ }^{18} \mathrm{~F}-\mathrm{FE}-\mathrm{PE} 2 \mathrm{I}$ shows faster kinetics and more favorable metabolism, with less production of a radiometabolite with intermediate lipophilicity (M1), which - in the case of ${ }^{11} \mathrm{C}-\mathrm{PE} 2 \mathrm{l}$ - has been shown to enter the rat brain. In this study, we compared DAT quantification with ${ }^{11} \mathrm{C}-\mathrm{PE} 2 \mathrm{I}$ and ${ }^{18} \mathrm{~F}-\mathrm{FE}-\mathrm{PE} 2 \mathrm{I}$ in nonhuman primates, using kinetic and graphical analysis with the input function of both the parent and the radiometabolite, to assess the potential contribution of the radiometabolite. Methods: Three rhesus monkeys were examined with ${ }^{11} \mathrm{C}-\mathrm{PE} 2 \mathrm{I}$ and ${ }^{18} \mathrm{~F}-\mathrm{FE}-\mathrm{PE} 2 \mathrm{I}$ using the HRRT system. Arterial input functions of the parent and radiometabolite M1 were measured. Kinetic and graphical analyses were applied using either the parent input (methods 1 and 3 ) or the parent plus radiometabolite input (methods 2 and 4). Outcome measures were distribution volumes $\left(V_{\mathrm{T}}\right.$ and $\left.V_{\mathrm{ND}}\right)$, specific-to-nondisplaceable tissue radioactivity ratio at equilibrium ( $B P_{\mathrm{ND}}$; parent input), and specific-to-nondisplaceable tissue radioactivity ratio at equilibrium in the presence of metabolites $\left(R_{\mathrm{T}}\right.$; parent plus radiometabolite input). Results: ${ }^{11} \mathrm{C}-\mathrm{PE} 2 \mathrm{I}$ showed higher distribution volumes than ${ }^{18} \mathrm{~F}-\mathrm{FE}-\mathrm{PE} 2 \mathrm{l}$ calculated with methods 1 and 3 (striatal $V_{\mathrm{T}}, \sim 300 \% ; V_{\mathrm{ND}}$ in cerebellum, $\sim 30 \%$ ). With methods 2 and $4, V_{\mathrm{T}}$ in the striatum was approximately $60 \%$ higher in the case of ${ }^{11} \mathrm{C}-\mathrm{PE} 2 \mathrm{I}$, whereas no difference in $V_{\mathrm{ND}}$ was found in the cerebellum. For each radioligand, $B P_{\mathrm{ND}}$ estimated with methods 1 and 3 tended to be higher than $R_{\mathrm{T}}$ estimated with methods 2 and 4 . However, the bias of $B P_{\mathrm{ND}}$, compared with $R_{\mathrm{T}}$, was much larger for ${ }^{11} \mathrm{C}-\mathrm{PE} 2 \mathrm{I}(40 \%-60 \%$ in the caudate and putamen) than for ${ }^{18} \mathrm{~F}-\mathrm{FE}-\mathrm{PE} 2 \mathrm{I}(<10 \%$ in the caudate and putamen). Conclusion: The direct comparison between the radioligands confirmed that ${ }^{18} \mathrm{~F}-\mathrm{FE}-$ PE2I shows faster kinetics and more favorable metabolism than ${ }^{11} \mathrm{C}-\mathrm{PE} 2 \mathrm{I}$. The kinetic and graphical analyses with the input function of the parent and radiometabolite showed that
\end{abstract}

Received Mar. 26, 2010; revision accepted Sep. 17, 2010.

For correspondence or reprints contact: Andrea Varrone, Karolinska Institutet, Department of Clinical Neuroscience, Centre for Psychiatry Research, R5:02, Karolinska Hospital, SE-17176, Stockholm, Sweden.

E-mail: andrea.varrone@ki.se

COPYRIGHT @ 2011 by the Society of Nuclear Medicine, Inc. the bias in $B P_{N D}$ was much lower for ${ }^{18} \mathrm{~F}-\mathrm{FE}-\mathrm{PE} 2 \mathrm{l}$ than for ${ }^{11} \mathrm{C}-\mathrm{PE} 2 \mathrm{I}$ and suggested that the lower production of the radiometabolite $\mathrm{M} 1$ would make ${ }^{18} \mathrm{~F}-\mathrm{FE}-\mathrm{PE} 2 \mathrm{I}$ more suitable for the DAT quantification. Further studies in humans are necessary to confirm these findings.

Key Words: molecular imaging; dopamine transporter; radiotracer tissue kinetics; binding potential; graphical analysis; metabolite

J Nucl Med 2011; 52:132-139

DOI: 10.2967/jnumed.110.077651

$N$

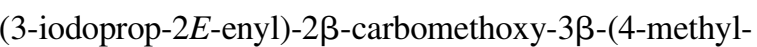
phenyl)nortropane labeled with ${ }^{11} \mathrm{C}\left({ }^{11} \mathrm{C}-\mathrm{PE} 2 \mathrm{I}\right)$ is an established radioligand for PET imaging of the dopamine transporter (DAT) (1). Several human studies have been performed with ${ }^{11} \mathrm{C}-\mathrm{PE} 2 \mathrm{I}$, and quantification methods have been fully evaluated using kinetic analysis and reference tissue methods (2-4). Although ${ }^{11} \mathrm{C}-\mathrm{PE} 2 \mathrm{I}$ is a suitable DAT radioligand, there are potential limitations for robust in vivo quantification. First, because of the slow kinetics and late peak equilibrium, accurate quantification requires imaging for longer than $90 \mathrm{~min}$ (5). For patients with Parkinson disease, it could be difficult to lie still in the PET scanner for such a long time, and a tracer with faster kinetics could be more advantageous for wide clinical applications. Second, ${ }^{11} \mathrm{C}$ PE2I is metabolized in 4-hydroxymethyl and 4-carboxyl analogs; the 4-hydroxymethyl radiometabolite has been found to enter the rat brain and accumulate in the striatum (6), likely showing affinity for the DAT and potentially interfering with the quantification. The other metabolite, the 4-carboxyl analog, has been found to be ionic, with a calculated octanol-water distribution constant at $\mathrm{pH} 7.4$ equal to 0.16 , and it is less likely to cross the blood-brain barrier (6).

We recently evaluated in nonhuman primates a fluoro-ethyl analog of PE2I- ${ }^{18} \mathrm{~F}-(E)-N$-(3-iodoprop-2-enyl)-2 $\beta$-car-

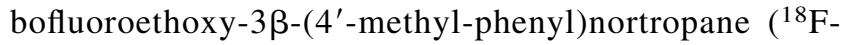
FE-PE2I)—and demonstrated its faster kinetics and 
more favorable metabolism, with less production of a radiometabolite with intermediate lipophilicity (7). In keeping with these initial observations, we wanted to further extend the evaluation of ${ }^{18} \mathrm{~F}-\mathrm{FE}-\mathrm{PE} 2 \mathrm{I}$ in nonhuman primates. The aim of this study was to directly compare the DAT quantification with ${ }^{11} \mathrm{C}$-PE2I and ${ }^{18} \mathrm{~F}-\mathrm{FE}-\mathrm{PE} 2 \mathrm{I}$ in the rhesus monkey (Macaca mulatta) brain.

In view of the production of at least 1 radiolabeled metabolite (the 4-hydroxymethyl analog) that could enter the brain, the quantification was performed with the assumption that the 4-carboxyl analog would not enter the brain and using different approaches. Kinetic analysis with a 2-tissuecompartment model (2-TCM) and the parent input function is the reported quantification method for ${ }^{11} \mathrm{C}$-PE2I $(2,4,5)$. Therefore, this method (method 1) was applied to the quantification of ${ }^{11} \mathrm{C}$-PE2I and ${ }^{18} \mathrm{~F}-\mathrm{FE}-\mathrm{PE} 2 \mathrm{I}$. In addition, the parent and radiometabolite input functions were used to evaluate the contribution of the radiometabolite to the DAT quantification. Because the radiometabolite likely has affinity for the DAT, in DAT-rich regions kinetic analysis would require a 4-tissue-compartment model with 8 rate constants. In this study, the 4 -tissue-compartment model was not applied, because a preliminary evaluation suggested that the model was not stable and the rate constants and outcome measures could not be reliably estimated. The contribution of the radiometabolite was then assessed in the following way. The input functions of the parent $\left(\mathrm{C}_{\mathrm{a}}{ }^{\mathrm{P}}\right)$ and the radiometabolite $\left(\mathrm{C}_{\mathrm{a}} \mathrm{M}\right)$ were combined in 1 input function $\left(\mathrm{C}_{\mathrm{a}}{ }^{\mathrm{P}+\mathrm{M}}\right)$. Kinetic analysis with a 2-TCM and the $\mathrm{C}_{\mathrm{a}}{ }^{\mathrm{P}+\mathrm{M}}$ input was applied (method 2), and the distribution volumes and binding potential $(B P)$ were compared with those obtained with method 1 . The outcome measures calculated with method 2 were considered the gold standard for the DAT quantification using kinetic analysis.

In addition, for each radioligand, 2 graphical analyses were used: the Logan graphical analysis (method 3), using the input $\mathrm{C}_{\mathrm{a}} \mathrm{P}(8)$, and a graphical analysis using the input $\mathrm{C}_{\mathrm{a}}{ }^{\mathrm{P}+\mathrm{M}}$ (9) (method 4). The outcome measures related to distribution volume and $B P$ obtained with and without the radiometabolite were compared. The outcome measures obtained with method 4 were considered the gold standard for the DAT quantification using graphical analysis. The graphical analysis does not make any assumption on the number of compartments and could be applied, with some limitations, also to the situation in which the metabolite has the affinity for the target. Finally, for each radioligand, the outcome measures obtained with methods 1 and 2 were compared with those obtained from methods 3 and 4 .

The prediction was that, because the radiometabolite would likely bind to the DAT, in the target and reference regions the distribution volume relative to $\mathrm{C}_{\mathrm{a}}{ }^{\mathrm{P}}$ would be higher than the distribution volume relative to $\mathrm{C}_{\mathrm{a}}{ }^{\mathrm{P}+\mathrm{M}}$. In addition, the $B P$ measured with $\mathrm{C}_{\mathrm{a}}{ }^{\mathrm{P}}$ would be higher than the $B P$ measured with $\mathrm{C}_{\mathrm{a}}{ }^{\mathrm{P}+\mathrm{M}}$, reflecting the degree of bias due to the radiometabolite entering the brain. The radio- ligand showing the least degree of bias would thus be preferable for the DAT quantification. Our prediction was that, because of a lower production of the radiometabolite with intermediate lipophilicity, ${ }^{18} \mathrm{~F}-\mathrm{FE}-\mathrm{PE} 2 \mathrm{I}$ would show a lower degree of bias than ${ }^{11} \mathrm{C}$-PE2I.

\section{MATERIALS AND METHODS}

Three rhesus monkeys (mean weight $\pm \mathrm{SD}, 5.2 \pm 0.8 \mathrm{~kg}$ ) were examined. The monkeys are owned by the Centre for Psychiatry Research, Department of Clinical Neuroscience, Karolinska Institutet, and housed in the Astrid Fagraeus Laboratory of the Swedish Institute for Infectious Disease Control. The study was approved by the Animal Ethics Committee of the Swedish Animal Welfare Agency and was performed according to the guidelines reported by Clark et al. (10). The anesthesia was induced by intramuscular injection of ketamine hydrochloride (12 mg/kg; Ketalar [Pfizer]) and maintained by the administration of a mixture of sevoflurane $(2 \%-8 \%), \mathrm{O}_{2}$, and medical air after endotracheal intubation. The head was immobilized with a fixation device (11). Body temperature was maintained by Bair Hugger (model 505; Arizant Health Care Inc.) and monitored by an oral thermometer. Electrocardiogram, heart rate, respiratory rate, oxygen saturation, and arterial blood pressure were continuously monitored throughout the experiments. In each monkey, 2 PET measurements were conducted using the HRRT system (Siemens Molecular Imaging) after intravenous administration of ${ }^{11} \mathrm{C}$-PE2I $(164 \pm 8 \mathrm{MBq})$, followed by ${ }^{18}$ F-FE-PE2I $(170 \pm 3 \mathrm{MBq}) 3 \mathrm{~h}$ later. In 1 monkey only, for technical reasons, the 2 PET measurements were conducted on 2 separate days, 6 mo apart. A catheter was inserted in an artery of the lower limb, and arterial blood was collected continuously for $3 \mathrm{~min}$ using an automated blood-sampling system at a speed of $3 \mathrm{~mL} / \mathrm{min}$ (ABSS; Allog AB). Blood samples $(1.5 \mathrm{~mL})$ were drawn at $3-5,15,30,45,60$, and $120 \mathrm{~min}$ for blood and plasma radioactivity and metabolite correction.

\section{Preparation of ${ }^{11} \mathrm{C}-\mathrm{PE} 2 \mathrm{l}$ and ${ }^{18} \mathrm{~F}-\mathrm{FE}-\mathrm{PE} 2 \mathrm{l}$}

${ }^{11} \mathrm{C}$-PE2I was prepared from its acid precursor $(0.5 \mathrm{mg})$ through a reaction with ${ }^{11} \mathrm{C}$-methyl triflate, tetrabutyl ammonium hydroxide $(0.4 \mathrm{M}, 4 \mu \mathrm{L})$, and acetone $(400 \mu \mathrm{L})$, as previously described (1). ${ }^{18}$ F-FE-PE2I was prepared from its acid precursor through a reaction with ${ }^{18} \mathrm{~F}$-2-bromo-1-fluoroethane in dimethylformamide $(400 \mu \mathrm{L})$ and sodium hydroxide $(5 \mathrm{M}, 12 \mu \mathrm{L})$ in $N, N$-dimethylformamide $(200 \mu \mathrm{L})$, as previously described (12). Both radioligands were formulated in a mixture of physiologically buffered saline, ethanol, and propylene glycol before final sterilization by filtration $(0.22 \mu \mathrm{m}$; Millex GV filter [Millipore]). The specific activities were $185 \mathrm{GBq} / \mu \mathrm{mol}$ or greater for ${ }^{11} \mathrm{C}-\mathrm{PE} 2 \mathrm{I}$ and 113 $\mathrm{GBq} / \mu \mathrm{mol}$ or greater for ${ }^{18} \mathrm{~F}-\mathrm{FE}-\mathrm{PE} 2 \mathrm{I}$ at time of injection, corresponding to a maximum injected mass of 0.2 and $0.3 \mathrm{nmol} / \mathrm{kg}$, respectively.

\section{PET Measurements}

A 6-min transmission scan using a single ${ }^{137} \mathrm{Cs}$ source was obtained immediately before the radioligand injection. List-mode data were acquired for $123 \mathrm{~min}$. PET images were reconstructed with a series of frames of increasing duration $(20 \mathrm{~s} \times 9,60 \mathrm{~s} \times 3$, $180 \mathrm{~s} \times 5$, and $360 \mathrm{~s} \times 17$ ) using the ordinary Poisson 3-dimensional ordered-subset expectation maximization algorithm, with 10 iterations and 16 subsets, including modeling of the point spread function, after correction for attenuation, randoms, and 
scatter. The resolution of the reconstructed images was $1.5 \mathrm{~mm}$ in full width at half maximum (13).

\section{Image Analysis}

Volumes of interest were delineated on coregistered PET/MR images; delineation was guided by an atlas of 1 rhesus monkey brain (14). Mean PET images of both radioligands were generated by averaging frames 1-13 using the software Vinci 2.54 (Max-Planck Institute for Neurological Research, Cologne) to generate a blood flow-like image. The MR image was manually coregistered to the average PET image using the FUSION tool in PMOD software (version 3.0; PMOD Technologies). In monkey 1, in which the 2 PET measurements were performed on separate days, the mean ${ }^{18}$ F-FE-PE2I PET image was coregistered to the mean ${ }^{11} \mathrm{C}-\mathrm{PE} 2 \mathrm{I}$ PET image. Volumes of interest for the caudate, putamen, midbrain, thalamus, cerebellum, and whole brain were drawn using PMOD 3.0.

Total-brain uptake was calculated by the total radioactivity from the whole-brain volume of interest expressed as percentage of the radioactivity injected. Decay-corrected time-activity curves for all regions were plotted over time. Radioactivity concentration was expressed as percentage standardized uptake value and calculated as radioactivity concentration $\left(\mathrm{kBq} / \mathrm{cm}^{3}\right) \div$ (radioactivity injected $[\mathrm{MBq}] /$ body weight $[\mathrm{kg}]) \times 100$. The cerebellum was considered the reference region; the volumes of interest were drawn on cerebellar hemispheres, excluding the midline structure that could contain DAT binding sites (15).

\section{Radiometabolite Analysis}

A reversed-phase high-performance liquid chromatography (HPLC) method was used to determine the percentages of radioactivity in monkey plasma that corresponded to unchanged radioligand and radiometabolites during the course of a PET measurement (16). The plasma $(0.5 \mathrm{~mL})$ obtained after centrifugation of blood at $2,000 \mathrm{~g}$ for $2 \mathrm{~min}$ was mixed with acetonitrile $(0.7$ $\mathrm{mL})$. The supernatant acetonitrile-plasma mixture $(1.1 \mathrm{~mL})$ and the precipitate obtained after centrifugation at 2,000g for $2 \mathrm{~min}$ were counted in a NaI well counter. Details of the well counter and the radio-HPLC system have been previously reported (7). In the HPLC system, acetonitrile (C) and phosphoric acid (10 mM) (D) were used as the mobile phase at $6.0 \mathrm{~mL} / \mathrm{min}$, according to the following program: 0-4.5 $\mathrm{min},(\mathrm{C} / \mathrm{D}) 25: 75 \rightarrow 80: 20 \mathrm{v} / \mathrm{v} ; 4.5-8.0 \mathrm{~min},(\mathrm{C} /$ D) $80: 20 \rightarrow 30: 70 \mathrm{v} / \mathrm{v}$; and 8.0-10.0 $\mathrm{min},(\mathrm{C} / \mathrm{D})$ 30:70 $\rightarrow$ 25:75 $\mathrm{v} / \mathrm{v}$. Peaks for radioactive compounds eluting from the column were integrated, and their areas - expressed as a percentage of the sum of the areas of all detected radioactive compounds-were decay-corrected to the time of injection on the HPLC.

\section{Quantification}

Kinetic analysis was performed with 2 methods. For method 1, a 2-TCM with the input $\mathrm{C}_{\mathrm{a}}{ }^{\mathrm{P}}$ with 4 rate constants- $K_{1}{ }^{\mathrm{P}}$ $\left(\mathrm{mL} \cdot \mathrm{cm}^{-3} \cdot \min ^{-1}\right), k_{2}{ }^{\mathrm{P}}\left(\min ^{-1}\right), k_{3}{ }^{\mathrm{P}}\left(\mathrm{min}^{-1}\right)$, and $k_{4}{ }^{\mathrm{P}}\left(\mathrm{min}^{-1}\right)-$ was used. In the caudate, putamen, midbrain, and thalamus, $k_{3}{ }^{\mathrm{P}}$ and $k_{4}{ }^{\mathrm{P}}$ are the rate constants describing the exchange of the tracer between the nondisplaceable $\left(C_{\mathrm{ND}}^{\mathrm{P}}\right)$ and the specifically bound $\left(C_{\mathrm{S}}{ }^{\mathrm{P}}\right)$ compartments (Supplemental Fig. 1A; supplemental materials are available online only at http://jnm.snmjournals.org). In the cerebellum, 2 rate constants, $k_{5}{ }^{\mathrm{P}}$ and $k_{6}{ }^{\mathrm{P}}$, describe the exchange of the tracer between the free $\left(C_{\mathrm{F}}^{\mathrm{P}}\right)$ and nonspecifically bound $\left(C_{\mathrm{NS}}^{\mathrm{P}}\right)$ compartments. Quantification of the DAT in human subjects with ${ }^{11} \mathrm{C}$-PE2I has shown that a 2 -TCM provides a better fitting than a 1-tissue-compartment model (1-TCM) in the cerebellum, suggesting the presence of a kinetically distinguished compartment (2).
The goodness of fit was assessed using the $\chi^{2}$ (sum of the squared discrepancies between data and model predictions divided by the number of degrees of freedom) and the model selection criterion (17). The identifiability of parameters was expressed by the coefficient of variation, which was calculated as SE/(estimate of the parameter) (17) and expressed as percentage (\%COV).

For method 2, a 2-TCM with the input $\mathrm{C}_{\mathrm{a}}{ }^{\mathrm{P}+\mathrm{M}}$ (parent $[\mathrm{P}]$ and radiometabolite [M1]) was used (Supplemental Fig. 1B). This method was considered the gold standard for the quantitative analysis with compartmental modeling because it takes into account the contribution of the radiometabolite. First, with the input $\mathrm{C}_{\mathrm{a}}{ }^{\mathrm{P}+\mathrm{M}}$, data in the cerebellum were fitted using a 2-TCM with 4 rate constants, $K_{1}{ }^{\mathrm{P}+\mathrm{M}}, k_{2}{ }^{\mathrm{P}+\mathrm{M}}, k_{5}{ }^{\mathrm{P}+\mathrm{M}}$, and $k_{6}{ }^{\mathrm{P}+\mathrm{M}}$, and a $1-\mathrm{TCM}$ with 2 rate constants, $K_{1}{ }^{\mathrm{P}+\mathrm{M}}$ and $k_{2}{ }^{\mathrm{P}+\mathrm{M}}$. The $\mathrm{F}$ test was used to assess whether the 2-TCM provided a significantly better fit than the 1-TCM (18). Once the 1-TCM was considered as good as the 2-TCM at describing the kinetics in the cerebellum, in the DAT-rich regions a 2-TCM with the input $\mathrm{C}_{\mathrm{a}}{ }^{\mathrm{P}+\mathrm{M}}$ was used, fixing $K_{1}{ }^{\mathrm{P}+\mathrm{M}} / k_{2}{ }^{\mathrm{P}+\mathrm{M}}$ to the value estimated in the cerebellum. Three rate constants, $K_{1}{ }^{\mathrm{P}+\mathrm{M}}$, $k_{3}{ }^{\mathrm{P}+\mathrm{M}}$, and $k_{4}{ }^{\mathrm{P}+\mathrm{M}}$, were estimated. This approach improved convergence of the fitting and reliability of the estimation of the parameters.

The outcome measures were $V_{\mathrm{T}}$ (DAT-rich regions) and $V_{\mathrm{ND}}$ (cerebellum) (19). The $B P$ was measured indirectly. In method 1 , specific-to-nondisplaceable tissue radioactivity ratio at equilibrium $\left(B P_{\mathrm{ND}}\right)$ equaled $V_{\mathrm{T}} / V_{\mathrm{ND}}-1$ (19); in method 2 , the $B P$ was referred to as $R_{\mathrm{T}}$ and was calculated in the same way as $B P_{\mathrm{ND}}$ from the distribution volumes in the target and reference obtained using $\mathrm{C}_{\mathrm{a}} \mathrm{P}+\mathrm{M}$. In each method, the total (free plus protein-bound) $\mathrm{C}_{\mathrm{a}}{ }^{\mathrm{P}}$ or $\mathrm{C}_{\mathrm{a}}{ }^{\mathrm{P}+\mathrm{M}}$ was used as an input function, and the radioactivity concentration in the blood was used for blood-volume correction, with a fixed blood volume fraction of 0.05 . The time delay between the arrival of the tracer at the ABSS detector and in the brain was estimated by a preliminary fitting of the whole-brain time-activity curve, with a $2-\mathrm{TCM}$ including 4 rate constants. The Marquardt-Levenberg algorithm for the iterative minimization of the cost function was used. Weights were calculated using the formula $\mathrm{w}_{\mathrm{i}}=1 / \sigma_{\mathrm{i}}{ }^{2}$, where $\sigma_{\mathrm{i}}^{2}$ was estimated from the average values of all time-activity curve data points, with constant variance over time (20). Differences in the \% COV and the estimates of the individual rate constants were assessed with an unpaired $t$ test, with a significance at $P$ less than 0.05 .

Graphical analysis was performed with methods 3 (Logan plot using the input $\mathrm{C}_{\mathrm{a}}{ }^{\mathrm{P}}(8)$ ) and 4 (graphical analysis with the input $\left.\mathrm{C}_{\mathrm{a}}{ }^{\mathrm{P}+\mathrm{M}}(9)\right)$.

In method 3 , the time of equilibrium, $t^{*}$, was estimated by fitting the whole-brain time-activity curve. The model searches the earliest sample until the deviation between the regression and all measurements is less than $10 \%$. The estimated value of $t^{*}$ was then used for measuring the slope of the linear part of the Logan plot. The outcome measure was $B P_{\mathrm{ND}}=V_{\mathrm{T}} / V_{\mathrm{ND}}-1$.

Method 4 was considered the gold standard for the quantification using graphical analysis. According to the method described in detail by Ichise et al. (9), in the presence of radiolabeled metabolite the equations for graphical analysis proposed by Logan et al. can be combined to derive the following equation:

$$
\frac{\int_{0}^{\mathrm{t}} \mathrm{C}_{\mathrm{b}}(\mathrm{t}) \mathrm{dt}}{\mathrm{C}_{\mathrm{b}}(\mathrm{t})}=\alpha(\mathrm{t}) \frac{\int_{0}^{\mathrm{t}} \mathrm{C}_{\mathrm{a}}{ }^{\mathrm{P}+\mathrm{M}}(\mathrm{t}) \mathrm{dt}}{\mathrm{C}_{\mathrm{b}}(\mathrm{t})}+\beta(\mathrm{t}) .
$$

Eq. 1

$\mathrm{C}_{\mathrm{a}}{ }^{\mathrm{P}+\mathrm{M}}$ is the plasma radioactivity of the parent and the radiometabolite, $C_{b}$ is the brain radioactivity, and $\alpha$ and $\beta$ are the slope 
and intercept when Equation 1 becomes linear. According to Ichise et al. (9),

$$
\alpha=[1 /(1+\delta)] \sum_{\mathrm{i}} V_{\mathrm{i}}^{\mathrm{P}}+[\delta /(1+\delta)] \sum_{\mathrm{i}} V_{\mathrm{i}}^{\mathrm{M}} .
$$

$V_{\mathrm{i}}^{\mathrm{P}}$ and $V_{\mathrm{i}}^{\mathrm{M}}$ are the distribution volumes caused by parent and metabolite, respectively, of the $\mathrm{i}^{\text {th }}$ compartment in a brain region.

If Equation 1 is calculated in the receptor-rich and in the receptor-free region, then $\alpha$ can be calculated for both regions $\left(\alpha_{R R}\right.$ and $\alpha_{R F}$, respectively), and the following outcome measure can be derived:

$$
R_{\mathrm{T}}=\alpha_{\mathrm{RR}} / \alpha_{\mathrm{RF}}-1
$$

$R_{\mathrm{T}}$ represents the specific-to-nondisplaceable tissue radioactivity ratio at equilibrium in the presence of metabolites. $R_{\mathrm{T}}$ is related to the $B P$ by the following equation:

$$
R_{\mathrm{T}}=B P_{\mathrm{ND}} /\left(1+\delta V_{\mathrm{ND}}^{\mathrm{M}} / V_{\mathrm{ND}}^{\mathrm{P}}\right)
$$$$
\text { Eq. } 4
$$

$\delta$ is the ratio of the plasma concentration of the metabolite to the parent at equilibrium and was estimated by extrapolating the plasma concentration of the parent and the radiometabolite and calculating the integral ratio according to the following:

$$
\delta=\frac{\int_{0}^{\infty} \mathrm{C}_{\mathrm{a}}^{\mathrm{M}}(\mathrm{t}) \mathrm{dt}}{\int_{0}^{\infty} \mathrm{C}_{\mathrm{a}}^{\mathrm{P}}(\mathrm{t}) \mathrm{dt}}
$$

Eq. 5

$V_{\mathrm{ND}}{ }^{\mathrm{M}}$ and $V_{\mathrm{ND}}^{\mathrm{P}}$ are the nondisplaceable distribution volumes of the radiometabolite and the parent, respectively. In method $4, t^{*}$ was estimated by fitting the whole-brain time-activity curve similarly to method 3 .

Kinetic and graphical analyses were performed using PMOD 3.0.

\section{RESULTS}

\section{Regional Brain Uptake and Kinetics}

Representative PET images and time-activity curves for ${ }^{11} \mathrm{C}$-PE2I and ${ }^{18} \mathrm{~F}-\mathrm{FE}-\mathrm{PE} 2 \mathrm{I}$ are shown in Figure 1 and Supplemental Figure 2, respectively. The radioligands demonstrated similar uptake and regional distribution in the rhesus monkey brain. However, ${ }^{18}$ F-FE-PE2I showed a faster washout from DAT-rich regions. For ${ }^{18}$ F-FE-PE2I, peak specific binding in the striatum and midbrain was reached between 20 and $40 \mathrm{~min}$ and for ${ }^{11} \mathrm{C}$-PE2I, later than $70 \mathrm{~min}$ in the striatum and at approximately $40 \mathrm{~min}$ in the midbrain.

\section{Radiometabolite Analysis}

HPLC analysis of plasma after the injection of ${ }^{11} \mathrm{C}$-PE2I and ${ }^{18} \mathrm{~F}$-FE-PE2I, which eluted after $5 \mathrm{~min}$, revealed the presence of 2 major peaks, M2 and M1, with retention times of approximately 3 and $4.5 \mathrm{~min}$ (Supplemental Fig. 3). For simplicity, M2 and M1 are used to indicate the 2 radiometabolites for both radioligands, although only the metabolites of ${ }^{11} \mathrm{C}$-PE2I have been previously identified. In the case of ${ }^{11} \mathrm{C}$-PE2I, the radiometabolite with intermediate lipophilicity, M1, was more abundant than M2, representing approximately $60 \%$ of the plasma radioactivity at 45 min after injection (Fig. 2). On the other hand, the more abundant radiometabolite of ${ }^{18} \mathrm{~F}$-FE-PE2I was the less lipophilic M2 ( $\sim 71 \%$ at $45 \mathrm{~min}$ after injection), whereas M1 was approximately $19 \%$ of the plasma radioactivity at $45 \mathrm{~min}$ after injection. The ratio at equilibrium between the radiometabolite $\mathrm{M} 1$ and the parent, $\delta$, was approximately 3 times higher for ${ }^{11} \mathrm{C}$-PE2I $(4.8 \pm 0.5)$ than for ${ }^{18}$ F-FE-PE2I $(1.7 \pm 2.2)$.

\section{Quantification}

Method 1. Figure 3 shows a representative parent input function and fitting with a 2 -TCM of ${ }^{11} \mathrm{C}$-PE2I and ${ }^{18} \mathrm{~F}-\mathrm{FE}-$ PE2I in monkey 2, demonstrating a good fitting in both high-density and reference regions. The time delays estimated for ${ }^{11} \mathrm{C}$-PE2I and ${ }^{18} \mathrm{~F}-\mathrm{FE}-\mathrm{PE} 2 \mathrm{I}$ were $11.5 \pm 4.9 \mathrm{~s}$ and $8.7 \pm 2.5 \mathrm{~s}$, respectively. A 1-TCM did not provide a good fitting by visual inspection and was not pursued for further analysis. The estimate and \%COV of the rate constants are reported in Supplemental Table 1. All rate constants tended to be higher in the case of ${ }^{11} \mathrm{C}$-PE2I, but there was no significant difference except for $k_{5}{ }^{\mathrm{P}}$ and $k_{6}{ }^{\mathrm{P}}$ in the cerebellum $(P<0.05)$. On the other hand, in the caudate and putamen, the $k_{4}{ }^{\mathrm{P}}$ of ${ }^{11} \mathrm{C}$-PE2I was significantly lower $(P<$ $0.05)$ than the $k_{4}{ }^{\mathrm{P}}$ of ${ }^{18} \mathrm{~F}-\mathrm{FE}-\mathrm{PE} 2 \mathrm{I}$. Overall, the rate constant $K_{1}{ }^{\mathrm{P}}$ had a lower $\% \mathrm{COV}$ than the rate constants $k_{2}{ }^{\mathrm{P}}-k_{6}{ }^{\mathrm{P}}$. The $\% \mathrm{COV}$ of all rate constants was similar for both radioligands, with the exception of $k_{2}{ }^{\mathrm{P}}$ in the midbrain and $k_{4}{ }^{\mathrm{P}}$ in the putamen, in which the \%COV for ${ }^{18} \mathrm{~F}$-FE-PE2I was significantly lower $(P<0.05)$ than for ${ }^{11} \mathrm{C}-\mathrm{PE} 2 \mathrm{I}$.

Method 2. For method 2, a preliminary evaluation in the cerebellum of the goodness of fit showed that the 2-TCM provided a significantly better fit than did the 1-TCM only in monkey 1 for both ${ }^{11} \mathrm{C}$-PE2I and ${ }^{18} \mathrm{~F}-\mathrm{FE}-\mathrm{PE} 2 \mathrm{I}(F>4.2$, $P<0.05)$. In monkeys 2 and 3 , in the case of ${ }^{11} \mathrm{C}$-PE2I neither model seemed to provide a good fit in the cerebellum (Fig. 4), with $\chi^{2}$ values between 19.2 and 31.4 and model selection criterion values between 1.6 and 2.2. On the other hand, as for ${ }^{18} \mathrm{~F}-\mathrm{FE}-\mathrm{PE} 2 \mathrm{I}$, the fitting in the cere-

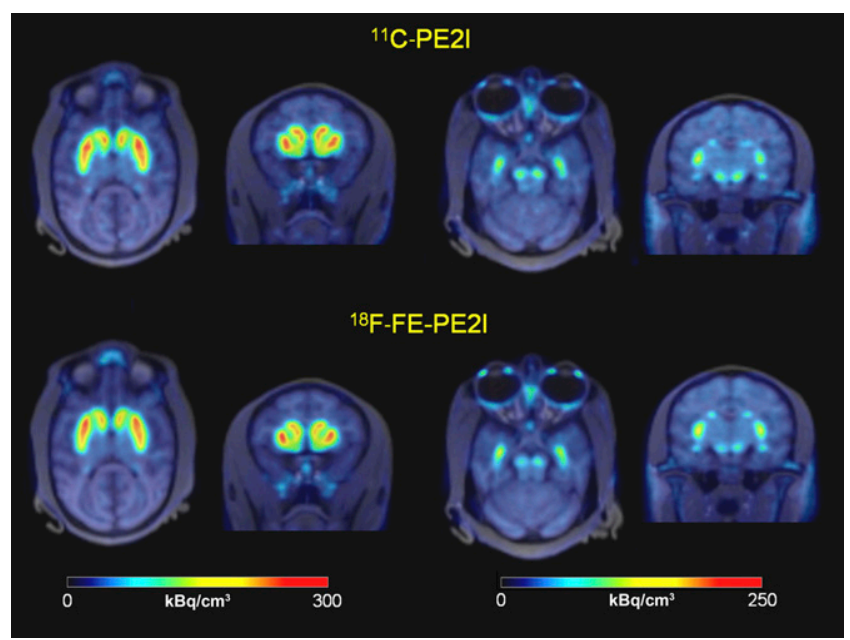

FIGURE 1. Representative fused PET/MR images of ${ }^{11} \mathrm{C}-\mathrm{PE} 2 \mathrm{I}$ and ${ }^{18} \mathrm{~F}-\mathrm{FE}-\mathrm{PE} 2 \mathrm{l}$ at level of striatum (first 2 columns) and midbrain (third and fourth columns). Frames from 9 to 123 min were averaged. 
FIGURE 2. Plasma composition of unchanged radioligands and their radiometabolites; data are reported as mean $\pm \mathrm{SD}$. Blue $={ }^{11} \mathrm{C}$-PE2I $(\mathrm{A})$; red $={ }^{18} \mathrm{~F}-\mathrm{FE}-\mathrm{PE} 2 \mathrm{I}(\mathrm{B})$.
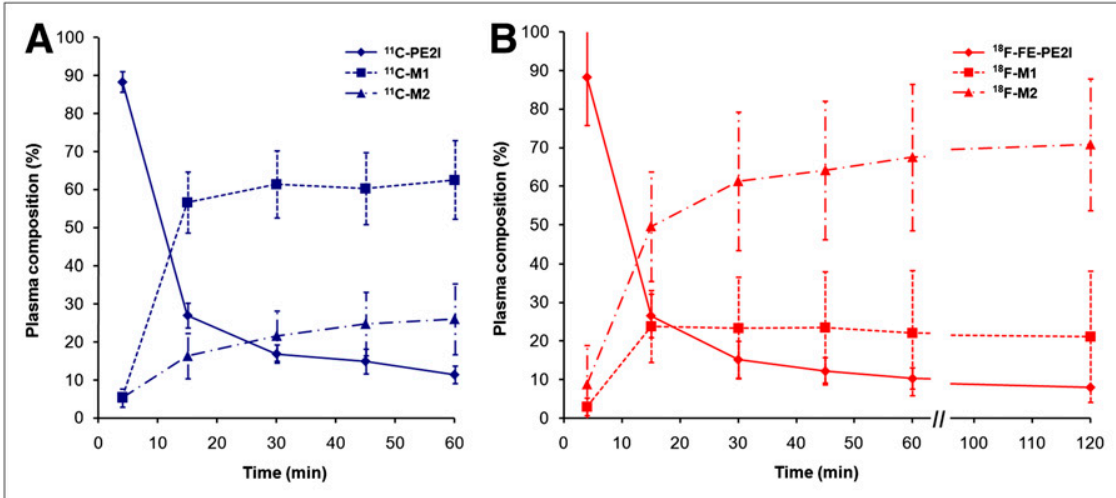

bellum was overall better (Fig. 4), with $\chi^{2}$ values between 1.7 and 2.4 and model selection criterion values between 4.5 and 4.9. In the case of ${ }^{11} \mathrm{C}$-PE2I, both models underestimated the area under the curve of the cerebellum in the first $20 \mathrm{~min}$ and gave an overestimation after 20 min (Fig. 4), suggesting that by combining the 2 input functions the fitting of the cerebellum was driven mainly by the parent in the initial phase and by the radiometabolite in the late phase.

We considered that even if the fitting for ${ }^{11} \mathrm{C}$-PE2I, compared with ${ }^{18} \mathrm{~F}-\mathrm{FE}-\mathrm{PE} 2 \mathrm{I}$, was poor in the case of monkeys 2 and 3 , the estimates of the ratio $K_{1}{ }^{\mathrm{P}+\mathrm{M}} / k_{2}{ }^{\mathrm{P}+\mathrm{M}}$ would not be affected to a large extent. Therefore, in method 2 in the high-density regions, data were fitted by fixing $K_{1}{ }^{\mathrm{P}+\mathrm{M}}$ / $k_{2}{ }^{\mathrm{P}+\mathrm{M}}$ to the value obtained in the cerebellum using a 1-TCM (Fig. 4). In the case of ${ }^{11}$ C-PE2I, the model pro- vided poorer fit and unreliable values of $k_{3}{ }^{\mathrm{P}+\mathrm{M}}$ and $k_{4}{ }^{\mathrm{P}+\mathrm{M}}$ in the midbrain and thalamus (Supplemental Table 2). The rate constant $K_{1}{ }^{\mathrm{P}+\mathrm{M}}$ had a lower $\% \mathrm{COV}$ than the rate constants $k_{3}{ }^{\mathrm{P}+\mathrm{M}}$ and $k_{4}{ }^{\mathrm{P}+\mathrm{M}}$, and the $\% \mathrm{COV}$ of all rate constants was similar for both radioligands (Supplemental Table 2).

\section{Comparison of Methods 1 and 2}

As for ${ }^{11} \mathrm{C}$-PE2I, in all monkeys method 1 provided a significantly better fit than method 2 in all target regions $(F>4.2, P<0.05)$. In the cerebellum, method 1 provided a significantly better fit than the 1-TCM with the input $\mathrm{C}_{\mathrm{a}}{ }^{\mathrm{P}+\mathrm{M}}(F>8.8, P<0.001)$. With regards to ${ }^{18} \mathrm{~F}-\mathrm{FE}-$ PE2I in monkey 1 , method 1 provided a significantly better fit than method 2 in all regions $(F>4.2, P<0.05)$. In monkey 2 , method 1 was better in the midbrain, thalamus,
FIGURE 3. Representative $\mathrm{C}_{\mathrm{a}}{ }^{\mathrm{P}}$ input function and curve fitting with 2-TCM (method 1) of ${ }^{11} \mathrm{C}$-PE2I (blue; $\mathrm{A}$ and $\mathrm{B}$ ) and ${ }^{18} \mathrm{~F}-\mathrm{FE}-\mathrm{PE} 2 \mathrm{I}$ (red; C and D). SUV = standardized uptake value.

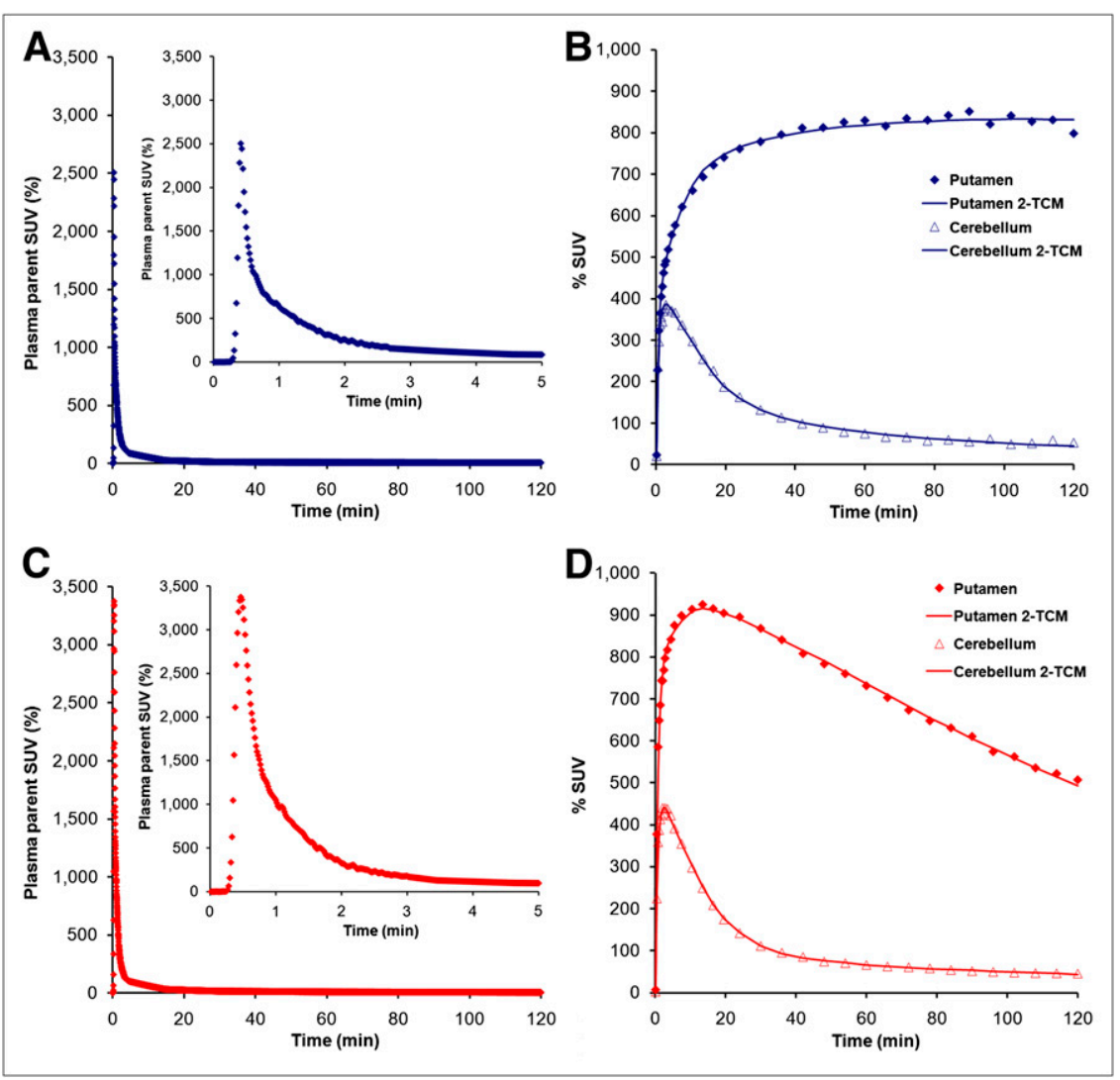




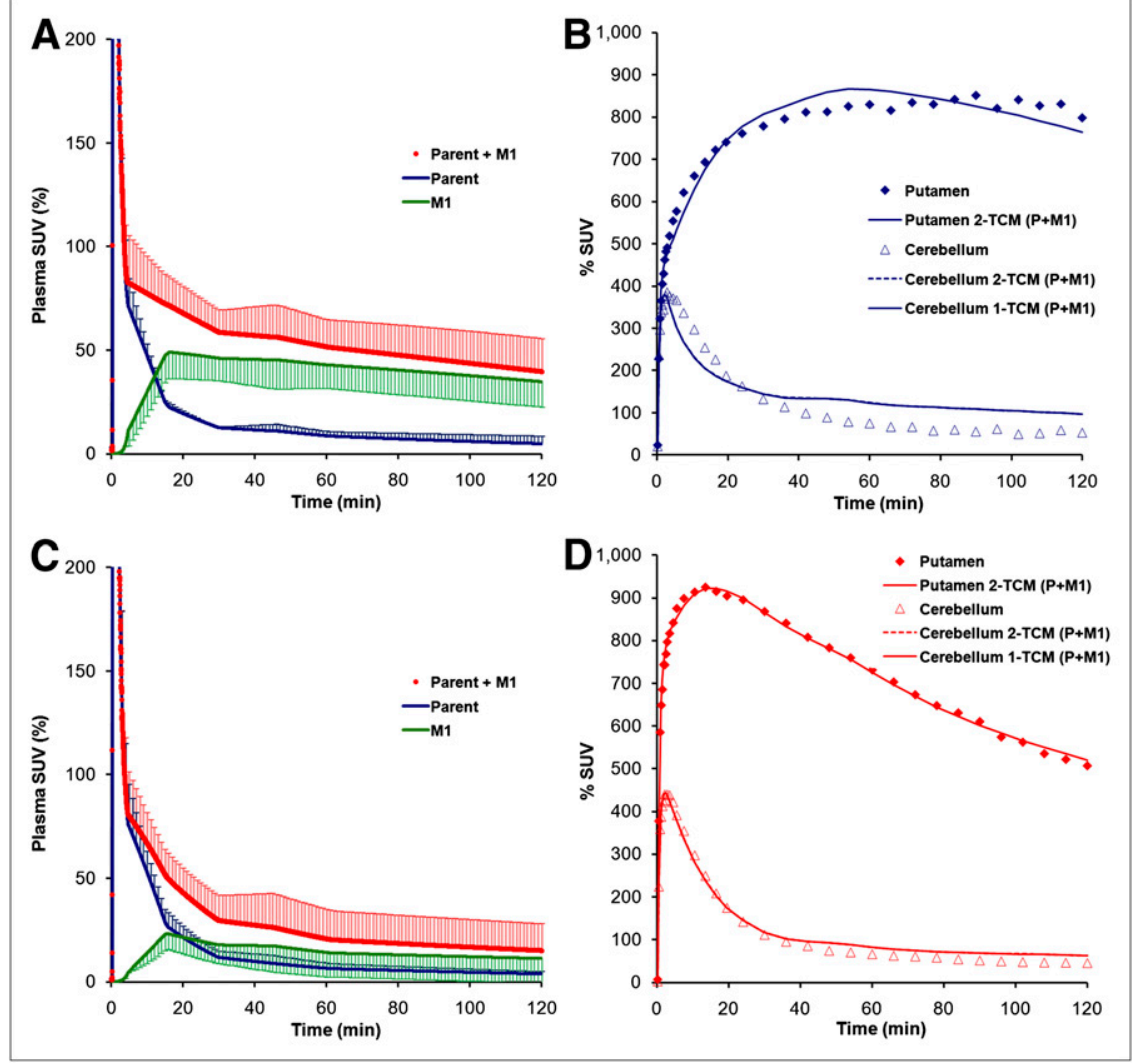

FIGURE 4. Average $\mathrm{C}_{\mathrm{a}}{ }^{\mathrm{P}+\mathrm{M}}$ input function from 3 monkeys and representative curve fitting with 2-TCM with $K_{1}{ }^{\mathrm{P}+\mathrm{M}} / k_{2}{ }^{\mathrm{P}+\mathrm{M}}$ fixed to the value of the cerebellum (method 2) of ${ }^{11} \mathrm{C}$-PE2I ( $\mathrm{A}$ and $\mathrm{B}$ ) and ${ }^{18} \mathrm{~F}-\mathrm{FE}-\mathrm{PE} 2 \mathrm{I}$ (C and D). Error bars represent SD. SUV = standardized uptake value. and cerebellum, but method 2 was better in the caudate and putamen $(F>4.2, P<0.05)$. In monkey 3 , method 1 provided a significantly better fit than method 2 in the caudate and putamen only $(F>4.2, P<0.05)$.

\section{Distribution Volumes in Methods 1 and 2}

The results of $V_{\mathrm{T}}$ and $V_{\mathrm{ND}}$ estimated using methods 1 and 2 are shown in Table 1 . In method $1,{ }^{11} \mathrm{C}-\mathrm{PE} 2 \mathrm{I}$ showed approximately $60 \%-300 \%$ higher $V_{\mathrm{T}}$ and approximately $30 \%$ higher $V_{\mathrm{ND}}$ values than ${ }^{18} \mathrm{~F}-\mathrm{FE}-\mathrm{PE} 2 \mathrm{I}$. In method 2 , the difference in $V_{\mathrm{T}}$ between ${ }^{11} \mathrm{C}$-PE2I and ${ }^{18} \mathrm{~F}$-FE-PE2I was lower $(\sim 5 \%-60 \%)$, whereas $V_{\mathrm{ND}}$ was almost identical for both ${ }^{11} \mathrm{C}-\mathrm{PE} 2 \mathrm{I}$ and ${ }^{18} \mathrm{~F}-\mathrm{FE}-\mathrm{PE} 2 \mathrm{I}$.

\section{Distribution Volumes in Methods $\mathbf{3}$ and $\mathbf{4}$}

In methods 3 and $4, t^{*}$ was estimated at 39 and $33 \mathrm{~min}$, respectively. Representative Logan and graphical analysis plots of ${ }^{11} \mathrm{C}$-PE2I and ${ }^{18}$ F-FE-PE2I in monkey 2 are reported in Supplemental Figure 4, and the correlations between distribution volumes obtained with kinetic and graphical analyses are reported in Supplemental Figure 5. Distribution volumes obtained with methods 3 and 4 were in good agreement with those obtained by kinetic analysis with methods 1 and 2 . For these methods, $R^{2}$ values were close to 1 and slopes of the regression lines close to the line of identity, except for a slight underestimation of method 3 versus method 1 in the case of ${ }^{11} \mathrm{C}-\mathrm{PE} 2 \mathrm{I}$ at the high range of $V_{\mathrm{T}}$ (Supplemental Fig. 5).

\section{Comparison of $\mathbf{B P}_{\mathrm{ND}}$ and $\mathbf{R}_{\mathbf{T}}$}

The results of $B P_{\mathrm{ND}}$ and $R_{\mathrm{T}}$ are reported in Table 2. $R_{\mathrm{T}}$ refers to the outcome measure of $B P$ in the presence of metabolite for methods 2 and 4 . In all regions, $B P_{\mathrm{ND}}$ and $R_{\mathrm{T}}$ were higher for ${ }^{11} \mathrm{C}$-PE2I than for ${ }^{18} \mathrm{~F}$-FE-PE2I. For each radioligand, $B P_{\mathrm{ND}}$ tended to be higher than $R_{\mathrm{T}}$. However, the differences between $B P_{\mathrm{ND}}$ and $R_{\mathrm{T}}$ were much larger for ${ }^{11} \mathrm{C}-\mathrm{PE} 2 \mathrm{I}$ (40\%-60\% in the caudate and putamen) than for ${ }^{18}$ F-FE-PE2I ( $<10 \%$ in the caudate and putamen).

\section{DISCUSSION}

The aim of this study was to directly compare the quantification of the DAT in the rhesus monkey brain using ${ }^{11} \mathrm{C}$-PE2I and ${ }^{18} \mathrm{~F}$-FE-PE2I. There were 2 main findings of this study: first, the results confirmed our previous observation that ${ }^{18} \mathrm{~F}-\mathrm{FE}-\mathrm{PE} 2 \mathrm{I}$ shows faster kinetics and more favorable metabolism than ${ }^{11} \mathrm{C}$-PE2I, with less production of the radiometabolite M1 that could interfere with the quantification. Second, we have more extensively evaluated the quantification of the 2 radioligands by collecting arterial blood samples and measuring the input function of the parent and radiometabolite; the results of the quantitative analysis suggested that the contribution of the radiometabolite to the DAT quantification was lower for ${ }^{18} \mathrm{~F}-\mathrm{FE}-\mathrm{PE} 2 \mathrm{I}$ than for ${ }^{11} \mathrm{C}$-PE2I. This suggestion was supported by the evidence that, when compared with the gold standard method including the radiometabolite, the distribution vol- 
TABLE 1

Distribution Volumes Estimated with Methods 1 and 2

\begin{tabular}{|c|c|c|c|c|c|c|}
\hline \multirow[b]{2}{*}{ Model } & \multirow[b]{2}{*}{ Radioligand } & \multicolumn{4}{|c|}{$V_{\mathrm{T}}\left(\mathrm{mL} / \mathrm{cm}^{3}\right)$} & \multirow{2}{*}{$\frac{V_{\mathrm{ND}}\left(\mathrm{mL} / \mathrm{cm}^{3}\right)}{\text { Cerebellum }}$} \\
\hline & & Caudate & Putamen & Midbrain & Thalamus & \\
\hline \multirow[t]{2}{*}{ 2-TCM, parent } & ${ }^{11} \mathrm{C}-\mathrm{PE} 2 \mathrm{I}$ & $\begin{array}{c}153.6 \pm 83.2 \\
(4.8 \% \pm 2.4 \%)\end{array}$ & $\begin{array}{l}154.3 \pm 98.7 \\
(3.8 \% \pm 1.7 \%)\end{array}$ & $\begin{array}{c}20.8 \pm 4.9 \\
(3.5 \% \pm 0.8 \%)\end{array}$ & $\begin{array}{c}9.9 \pm 3.5 \\
(5.9 \% \pm 6.2 \%)\end{array}$ & $\begin{array}{c}5.3 \pm 1.2 \\
(3.6 \% \pm 1.3 \%)\end{array}$ \\
\hline & ${ }^{18}$ F-FE-PE2I & $\begin{array}{c}36.9 \pm 3.2 \\
(2.1 \% \pm 0.9 \%)\end{array}$ & $\begin{array}{c}37.1 \pm 3.9 \\
(1.9 \% \pm 0.7 \%)\end{array}$ & $\begin{array}{c}8.9 \pm 0.6 \\
(3.0 \% \pm 0.7 \%)\end{array}$ & $\begin{array}{c}6.2 \pm 0.5 \\
(10.1 \% \pm 5.4 \%)\end{array}$ & $\begin{array}{c}4.1 \pm 0.3 \\
(9.2 \% \pm 2.9 \%)\end{array}$ \\
\hline \multirow[t]{2}{*}{$\begin{array}{l}\text { 2-TCM, parent } \\
\text { plus M1 }\end{array}$} & ${ }^{11} \mathrm{C}-\mathrm{PE} 2 \mathrm{I}$ & $\begin{array}{c}37.8 \pm 41.6 \\
(2.3 \% \pm 2.1 \%)\end{array}$ & $\begin{array}{c}41.0 \pm 48.2 \\
(1.9 \% \pm 1.6 \%)\end{array}$ & $\begin{array}{c}7.7 \pm 5.6 \\
(1.9 \% \pm 0.7 \%)\end{array}$ & $\begin{array}{c}3.8 \pm 1.9 \\
(4.1 \% \pm 1.2 \%)\end{array}$ & $\begin{array}{c}2.4 \pm 0.7 \\
(5.2 \% \pm 1.4 \%)\end{array}$ \\
\hline & ${ }^{18} \mathrm{~F}-\mathrm{FE}-\mathrm{PE} 2 \mathrm{I}$ & $\begin{array}{c}20.9 \pm 6.0 \\
(1.5 \% \pm 1.0 \%)\end{array}$ & $\begin{array}{c}21.2 \pm 6.6 \\
(1.4 \% \pm 0.8 \%)\end{array}$ & $\begin{array}{c}5.5 \pm 1.3 \\
(1.9 \% \pm 0.4 \%)\end{array}$ & $\begin{array}{c}3.5 \pm 0.5 \\
(2.9 \% \pm 1.5 \%)\end{array}$ & $\begin{array}{c}2.3 \pm 0.3 \\
(1.8 \% \pm 0.2 \%)\end{array}$ \\
\hline
\end{tabular}

Data are mean $\pm \mathrm{SD}$, and corresponding $\% \mathrm{COV}$ of estimates are in parentheses.

ume and the $B P$ showed a lower bias in the case of ${ }^{18} \mathrm{~F}-\mathrm{FE}-$ PE2I than in the case of ${ }^{11} \mathrm{C}$-PE2I.

\section{Method 1}

In method 1, the kinetic rate constants tended to be more reliably identified in the case of ${ }^{18} \mathrm{~F}$-FE-PE2I. The value of $k_{3}{ }^{\mathrm{P}}$ tended to be higher for ${ }^{11} \mathrm{C}-\mathrm{PE} 2 \mathrm{I}$, but the difference with ${ }^{18}$ F-FE-PE2I was not statistically significant. On the other hand, $k_{4}{ }^{\mathrm{P}}$ was significantly higher for ${ }^{18} \mathrm{~F}$-FE-PE2I in the caudate and putamen. The difference in $k_{4}{ }^{\mathrm{P}}$ was the most evident and relates to the faster washout of ${ }^{18} \mathrm{~F}-\mathrm{FE}-$ PE2I from the brain and to the lower $B P_{\mathrm{ND}}$ observed for this radioligand than for ${ }^{11} \mathrm{C}$-PE2I. The results of method 1 also showed a larger $k_{5}{ }^{\mathrm{P}}$ and $k_{6} \mathrm{P}$ in the cerebellum. It is likely that in view of the higher plasma concentration of the radiometabolite M1 for ${ }^{11} \mathrm{C}$-PE2I than for ${ }^{18} \mathrm{~F}$-FE-PE2I, the larger $k_{5}{ }^{\mathrm{P}}$ and $k_{6}{ }^{\mathrm{P}}$ could be also related to the higher contribution of the radiometabolite in the nondisplaceable compartment.

\section{Method 2}

Compared with the model using the input $\mathrm{C}_{\mathrm{a}}{ }^{\mathrm{P}}$, the model using the input $\mathrm{C}_{\mathrm{a}} \mathrm{P}+\mathrm{M}$ did not improve the fitting of the data. On the other hand, in all regions method 1 provided a better fit in all monkeys in the case of ${ }^{11} \mathrm{C}$-PE2I and in the first monkey in the case of ${ }^{18}$ F-FE-PE2I, suggesting that the combination of the parent plus radiometabolite likely increased the noise of the input function. In addition, the input was represented mainly by the parent in the initial $20 \mathrm{~min}$ and by the radiometabolite thereafter. This phenomenon was more evident in the case of ${ }^{11} \mathrm{C}$-PE2I, in which the fraction of ${ }^{11} \mathrm{C}$ M1 was relatively higher, and well exemplified by the fitting of the cerebellum (Supplemental Appendix A).

For simplicity, we kept the nomenclature of $V_{\mathrm{T}}$ and $V_{\mathrm{ND}}$ when referring to the distribution volumes obtained by methods 2 and 4 . When the distribution volumes obtained with the 2 methods were compared, a good correlation across all regions was found for both ${ }^{11} \mathrm{C}$-PE2I and ${ }^{18} \mathrm{~F}$ FE-PE2I. Because method 4 does not make any assumption on the number of compartments, we can argue that method 2 provided reasonable estimates of the distribution volumes, although it was not superior to method 1 .

\section{Method 3}

The Logan graphical analysis showed good agreement between outcome measures of ${ }^{11} \mathrm{C}$-PE2I and ${ }^{18} \mathrm{~F}-\mathrm{FE}-\mathrm{PE} 2 \mathrm{I}$ with method 1 . In the case of ${ }^{11} \mathrm{C}$-PE2I, a slight underestimation of $V_{\mathrm{T}}$ and $B P_{\mathrm{ND}}$ was seen in the caudate and putamen. This underestimation has already been reported (2) and is likely related to the slow kinetics of ${ }^{11} \mathrm{C}$-PE2I, which renders the estimation of $t^{*}$ less reliable. The better agreement in the case of ${ }^{18} \mathrm{~F}-\mathrm{FE}-\mathrm{PE} 2 \mathrm{I}$ between $V_{\mathrm{T}}$ and $B P_{\mathrm{ND}}$ estimated with the graphical and the kinetic analyses would

TABLE 2

Binding Potential Values Calculated with Kinetic and Graphical Analyses

\begin{tabular}{|c|c|c|c|c|c|c|c|c|}
\hline \multirow[b]{2}{*}{ Region } & \multicolumn{4}{|c|}{${ }^{11} \mathrm{C}-\mathrm{PE} 2 \mathrm{I}$} & \multicolumn{4}{|c|}{${ }^{18} \mathrm{~F}-\mathrm{FE}-\mathrm{PE} 2 \mathrm{I}$} \\
\hline & $\begin{array}{c}B P_{\mathrm{ND},} \text { 2-TCM } \\
(\text { Method 1) }\end{array}$ & $\begin{array}{l}R_{\mathrm{T},} 2-\mathrm{TCM} \\
\text { (Method 2) }\end{array}$ & $\begin{array}{c}B P_{\mathrm{ND},} \text { Logan } \\
\text { (Method 3) }\end{array}$ & $\begin{array}{c}R_{\mathrm{T}, \mathrm{GA}} \\
\text { (Method 4) }\end{array}$ & $\begin{array}{c}B P_{\mathrm{ND},} \text { 2-TCM } \\
(\text { Method 1) }\end{array}$ & $\begin{array}{l}R_{\mathrm{T}}, 2-\mathrm{TCM} \\
\text { (Method 2) }\end{array}$ & $\begin{array}{c}B P_{\mathrm{ND}}, \text { Logan } \\
\text { (Method 3) }\end{array}$ & $\begin{array}{c}R_{\mathrm{T}, \mathrm{GA}} \\
\text { (Method 4) }\end{array}$ \\
\hline Caudate & $26.7 \pm 8.7$ & $12.8 \pm 11.7$ & $21.1 \pm 6.9$ & $13.4 \pm 7.9$ & $8.1 \pm 0.5$ & $7.8 \pm 1.4$ & $8.2 \pm 0.1$ & $7.6 \pm 0.4$ \\
\hline Putamen & $26.4 \pm 11.3$ & $13.7 \pm 13.8$ & $21.9 \pm 9.6$ & $14.1 \pm 9.7$ & $8.1 \pm 0.9$ & $7.9 \pm 1.7$ & $8.3 \pm 0.5$ & $7.7 \pm 0.6$ \\
\hline Midbrain & $2.9 \pm 0.2$ & $2.0 \pm 1.3$ & $2.5 \pm 0.1$ & $2.2 \pm 0.3$ & $1.2 \pm 0.2$ & $1.3 \pm 0.3$ & $1.2 \pm 0.1$ & $1.3 \pm 0.0$ \\
\hline Thalamus & $0.8 \pm 0.2$ & $0.6 \pm 0.3$ & $0.6 \pm 0.1$ & $0.7 \pm 0.1$ & $0.5 \pm 0.0$ & $0.5 \pm 0.0$ & $0.4 \pm 0.1$ & $0.5 \pm 0.1$ \\
\hline
\end{tabular}

Data are mean $\pm \mathrm{SD}, \mathrm{GA}=$ graphical analysis 
suggest that ${ }^{18} \mathrm{~F}-\mathrm{FE}-\mathrm{PE} 2 \mathrm{I}$ is more suitable for the DAT quantification using the graphical approach.

\section{Method 4}

The graphical analysis of method 4 uses the input $\mathrm{C}_{\mathrm{a}}{ }^{\mathrm{P}+\mathrm{M}}$ to estimate graphically $\alpha_{\mathrm{RR}}\left(V_{\mathrm{T}}\right)$ and $\alpha_{\mathrm{RF}}\left(V_{\mathrm{ND}}\right)$ and to derive $R_{\mathrm{T}}$ (Eq. 3). In the original description, the method was used for the quantification of ${ }^{123}$ I-epidepride in the presence of a lipophilic metabolite not binding to the $\mathrm{D}_{2}$ receptor (17). When the metabolite contributes only to the nondisplaceable binding, it is possible to estimate the true $B P$ relative to $C_{a}{ }^{P}$, according to $B P_{P}=(1+\delta)\left(\alpha_{R R}-\alpha_{R F}\right)$ from the study by Ichise et al. (9). However, preclinical data suggest that ${ }^{11} \mathrm{C}-\mathrm{M} 1$ binds to the DAT and would contribute to the specific and the nondisplaceable binding. Therefore, the term $\alpha_{R R}-\alpha_{R F}$ would still contain the proportion of specific binding due to the radiometabolite, and the multiplication by the term $(1+\delta)$ would introduce a bias due to the relative abundance of the radiometabolite and its affinity to the DAT. Thus, in our case only the total distribution volume of the parent plus radiometabolite and $R_{\mathrm{T}}$ could be calculated.

\section{Comparison of Outcome Measures}

In the case of ${ }^{11} \mathrm{C}-\mathrm{PE} 2 \mathrm{I}$, the bias of $V_{\mathrm{T}}$ in methods 1 and 3 , compared with methods 2 and 4, was larger in the caudate and putamen $(\sim 75 \%-80 \%)$ than in the midbrain and thalamus $(\sim 65 \%)$ and larger than the bias of $V_{\mathrm{ND}}(\sim 60 \%)$. On the other hand, in the case of ${ }^{18}$ F-FE-PE2I, the bias of $V_{\mathrm{T}}$ and $V_{\mathrm{ND}}$ in methods 1 and 3, as compared with methods 2 and 4 , was similar ( $\sim 40 \%)$ across all regions. Thus, it seems likely that, for ${ }^{11} \mathrm{C}-\mathrm{PE} 2 \mathrm{I}$, the contribution of ${ }^{11} \mathrm{C}-\mathrm{M} 1$ would be larger for the high-density regions than for the low-density and reference regions, and that for ${ }^{18} \mathrm{~F}-\mathrm{FE}$ PE2I, the contribution of ${ }^{18} \mathrm{~F}-\mathrm{M} 1$ would be similar for all regions. The similar effect in all regions produced virtually no bias in the $B P$ as demonstrated by the differences between $B P_{\mathrm{ND}}$ and $R_{\mathrm{T}}$, suggesting that ${ }^{18} \mathrm{~F}$-FE-PE2I might be more suitable than ${ }^{11} \mathrm{C}$-PE2I when reference region methods are used. The lower $B P$ is not a limitation because the capability of ${ }^{18} \mathrm{~F}-\mathrm{FE}-\mathrm{PE} 2 \mathrm{I}$ to visualize extrastriatal regions such as the midbrain was similar to that of ${ }^{11} \mathrm{C}$-PE2I.

\section{CONCLUSION}

The direct comparison in nonhuman primates suggested that ${ }^{18} \mathrm{~F}$-FE-PE2I could be more suitable than ${ }^{11} \mathrm{C}$-PE2I as a radioligand for in vivo quantification of the DAT (Supplemental Appendix B). Further studies are necessary to confirm whether the differences between the 2 radioligands in metabolism, kinetics, and quantification also apply to human subjects.

\section{ACKNOWLEDGMENTS}

We thank Gudrun Nylen and the staff of the PET Centre at Karolinska Institutet for excellent assistance in the conduction of the PET studies, and Cyrill Burger (PMOD group) for helpful discussion on kinetic and graphical analysis. The study has been supported by FP6-project DiMI, LSHB-CT-2005-512146.

\section{REFERENCES}

1. Halldin C, Erixon-Lindroth N, Pauli S, et al. $\left[{ }^{11} \mathrm{C}\right] \mathrm{PE} 2 \mathrm{I}$ : a highly selective radioligand for PET examination of the dopamine transporter in monkey and human brain. Eur J Nucl Med Mol Imaging. 2003;30:1220-1230.

2. Jucaite A, Odano I, Olsson H, Pauli S, Halldin C, Farde L. Quantitative analyses of regional $\left[{ }^{11} \mathrm{C}\right] \mathrm{PE} 2 \mathrm{I}$ binding to the dopamine transporter in the human brain: a PET study. Eur J Nucl Med Mol Imaging. 2006;33:657-668.

3. Leroy C, Comtat C, Trebossen R, Syrota A, Martinot JL, Ribeiro MJ. Assessment of ${ }^{11} \mathrm{C}$-PE2I binding to the neuronal dopamine transporter in humans with the high-spatial-resolution PET scanner HRRT. J Nucl Med. 2007;48: $538-546$.

4. Hirvonen J, Johansson J, Teras M, et al. Measurement of striatal and extrastriatal dopamine transporter binding with high-resolution PET and $\left[{ }^{11} \mathrm{C}\right] \mathrm{PE} 2 \mathrm{I}$ : quantitative modeling and test-retest reproducibility. J Cereb Blood Flow Metab. 2008;28:1059-1069.

5. DeLorenzo C, Kumar JS, Zanderigo F, Mann JJ, Parsey RV. Modeling considerations for in vivo quantification of the dopamine transporter using $\left[{ }^{11} \mathrm{C}\right] \mathrm{PE} 2 \mathrm{I}$ and positron emission tomography. J Cereb Blood Flow Metab. 2009;29: 1332-1345.

6. Shetty HU, Zoghbi SS, Liow JS, et al. Identification and regional distribution in rat brain of radiometabolites of the dopamine transporter PET radioligand $\left[{ }^{11} \mathrm{C}\right]$ PE2I. Eur J Nucl Med Mol Imaging. 2007;34:667-678.

7. Varrone A, Steiger C, Schou M, et al. In vitro autoradiography and in vivo evaluation in cynomolgus monkey of $\left[{ }^{18} \mathrm{~F}\right] \mathrm{FE}-\mathrm{PE} 2 \mathrm{I}$, a new dopamine transporter PET radioligand. Synapse. 2009;63:871-880.

8. Logan J, Fowler JS, Volkow ND, et al. Graphical analysis of reversible radioligand binding from time-activity measurements applied to $\left[\mathrm{N}^{11} \mathrm{C}-\mathrm{methyl}\right]-$ (-)-cocaine PET studies in human subjects. J Cereb Blood Flow Metab. 1990;10:740-747.

9. Ichise M, Fujita M, Seibyl JP, et al. Graphical analysis and simplified quantification of striatal and extrastriatal dopamine $\mathrm{D}_{2}$ receptor binding with $\left[{ }^{123} \mathrm{I}\right]$ epidepride SPECT. J Nucl Med. 1999;40:1902-1912.

10. Clark JD, Gebhart GF, Gonder JC, Keeling ME, Kohn DF. Special report: the 1996 guide for the care and use of laboratory animals. ILAR J. 1997;38:41-48.

11. Karlsson P, Farde L, Halldin C, et al. PET examination of $\left[{ }^{11} \mathrm{C}\right] \mathrm{NNC} 687$ and $\left[{ }^{11} \mathrm{C}\right]$ NNC 756 as new radioligands for the D1-dopamine receptor. Psychopharmacology (Berl). 1993;113:149-156.

12. Schou M, Steiger C, Varrone A, Guilloteau D, Halldin C. Synthesis, radiolabeling and preliminary in vivo evaluation of $\left[{ }^{18} \mathrm{~F}\right] \mathrm{FE}-\mathrm{PE} 2 \mathrm{I}$, a new probe for the dopamine transporter. Bioorg Med Chem Lett. 2009;19:4843-4845.

13. Varrone A, Sjoholm N, Eriksson L, Gulyas B, Halldin C, Farde L. Advancement in PET quantification using 3D-OP-OSEM point spread function reconstruction with the HRRT. Eur J Nucl Med Mol Imaging. 2009;36:1639-1650.

14. Saleem KS, Logothesis NK. A Combined MRI and Histology Atlas of the Rhesus Monkey Brain in Stereotaxic Coordinates. 1st ed. Oxford, U.K.: Academic Press; 2007.

15. Melchitzky DS, Lewis DA. Tyrosine hydroxylase- and dopamine transporterimmunoreactive axons in the primate cerebellum: evidence for a lobular- and laminarspecific dopamine innervation. Neuropsychopharmacology. 2000;22:466-472.

16. Halldin C, Swahn CG, Farde L, Sedvall G. Radioligand disposition and metabolism: key information in early drug development. In: Comar D, ed. PET for Drug Development and Evaluation. Dordrecht, The Netherlands: Kluwer Academic; 1995:55-65.

17. Fujita M, Seibyl JP, Verhoeff NP, et al. Kinetic and equilibrium analyses of $\left[{ }^{123} \mathrm{I}\right]$ epidepride binding to striatal and extrastriatal dopamine $\mathrm{D}_{2}$ receptors. Synapse. 1999;34:290-304.

18. Carson RE. Parameter estimation in PET. In: Phelps M, Schelbert H, eds. Positron Emission Tomography and Autoradiography: Principles and Applications for the Brain and the Heart. New York, New York: Raven Press; 1986:287-346.

19. Innis RB, Cunningham VJ, Delforge J, et al. Consensus nomenclature for in vivo imaging of reversibly binding radioligands. J Cereb Blood Flow Metab. 2007;27:1533-1539.

20. Yaqub M, Boellaard R, Kropholler MA, Lammertsma AA. Optimization algorithms and weighting factors for analysis of dynamic PET studies. Phys Med Biol. 2006;51:4217-4232. 